Article

\title{
Depression Treatment Status of Economically Disadvantaged African American Older Adults
}

\author{
Sharon Cobb ${ }^{1}$, Mohsen Bazargan 2,3, Jessica Castro Sandoval ${ }^{4}$, Cheryl Wisseh ${ }^{2,5}$, \\ Meghan C. Evans ${ }^{3}$ and Shervin Assari ${ }^{2, *(1)}$ \\ 1 School of Nursing, Charles R Drew University of Medicine and Science, Los Angeles, CA 90059, USA; \\ sharoncobb1@cdrewu.edu \\ 2 Department of Family Medicine, Charles R Drew University of Medicine and Science, Los Angeles, \\ CA 90059, USA; Mohsenbazargan@cdrewu.edu (M.B.); cherylwisseh@cdrewu.edu (C.W.) \\ 3 Department of Family Medicine, University of California Los Angeles (UCLA), Los Angeles, CA 90095, USA; \\ meg.e.carlsen@gmail.com \\ 4 School of Public Health, Charles R Drew University of Medicine and Science, Los Angeles, CA 90059, USA; \\ jessicacastrosandoval@cdrewu.edu \\ 5 Department of Pharmacy Practice, West Coast University School of Pharmacy, Los Angeles, CA 91606, USA \\ * Correspondence: assari@umich.edu; Tel.: +1-734-363-2678
}

Received: 9 February 2020; Accepted: 4 March 2020; Published: 7 March 2020

check for updates

\begin{abstract}
Background: It is known that depression remains largely untreated in underserved communities. Hence, it is desirable to gain more knowledge on the prevalence and correlates of untreated depression among African-American (AA) older adults in economically disadvantaged areas. This knowledge may have the public health benefit of improving detection of AA older adults with depression who are at high risk of not receiving treatment, thereby reducing this health disparity. Objective: To study health and social correlates of untreated depression among AA older adults in economically disadvantaged areas. Methods: Between 2015 and 2018, this cross-sectional survey was conducted in South Los Angeles. Overall, 740 AA older adults who were 55+ years old entered this study. Independent variables were age, gender, living arrangement, insurance type, educational attainment, financial strain, chronic medical conditions, and pain intensity. Untreated depression was the dependent variable. Logistic and polynomial regression models were used to analyze these data. Results: According to the polynomial regression model, factors such as number of chronic medical conditions and pain intensity were higher in individuals with depression, regardless of treatment status. As our binary logistic regression showed, age, education, and number of providers were predictive of receiving treatment for depression. Conclusion: Age, educational attainment, number of providers (as a proxy of access to and use of care) may be useful to detect AA older adults with depression who are at high risk of not receiving treatment. Future research may focus on decomposition of the role of individual-level characteristics and health system-level characteristics that operate as barriers and facilitators to AA older adults receiving treatment for depression.
\end{abstract}

Keywords: depression; African Americans; depressive symptoms; ethnic groups; race

\section{Background}

Depression is acknowledged as a leading cause of disability and chronic disease burden, and is rapidly increasing among older adults [1]. Even more concerning, this mental health problem is largely untreated for socioeconomically underserved older adults, such as older African Americans (AAs), leading to poor mental and physical health outcomes [1]. It is well established that AAs experience disparities in depression diagnosis and treatment, such as late diagnosis and untreated depressive symptoms [2,3]. However, research over decades has shown depressive symptoms are 
more prevalent in AA populations [4-6]. Furthermore, depression among older AAs tends to be a prolonged, chronic, and severely debilitating condition, leading to decreased daily functioning and health status. Older AAs managing multimorbidity and polypharmacy are more likely to develop depression $[7,8]$. Findings from the Health Outcome Survey (HOM) that analyzed the prevalence of depression with the Patient Health Questionnaire-2 (PHQ-2) instrument revealed that $16 \%$ of older AAs and 9\% of non-Hispanic Whites experienced depression [9].

In regard to care, multiple studies have found that older AAs are less likely to receive professional treatment for depression than Whites [10-15]. A national population study of Medicaid recipients found that older AAs were more likely to be untreated for depression compared to Whites, Asians, and Hispanic groups [16]. Recent data from the Center for Medicare and Medicaid Services (2017) indicated that the rate of submitted reimbursement claims for depression treatment by health care providers was higher among older non-Hispanic Whites (16\%) compared to older AAs (11\%). Furthermore, one study found that older AAs are two times more likely than non-Hispanic Whites to receive no pharmacological treatment for depression [16]. Another study (2011) revealed that AAs were less likely than Whites to receive anti-depressant medication following primary care and psychiatry visits. Disparities also exist in regard to non-pharmacological treatment modalities for older AAs as they are less likely to receive counseling, referrals for counseling, or supportive care during primary care visits [17].

Management and treatment of depression can be complex and challenging for older adults, but even more for older AAs, who are less likely to receive care [18]. A higher need for depression treatment exists among those managing multiple chronic health conditions, decreased functional status, and traumatic life events [19]. Treatment of depression in older adults may be difficult due to a higher risk of adverse events, pharmacological interactions, and inappropriate medication use [20]. Untreated depression can result in serious consequences for older adults such as increased disability, poorer self-rated health, and greater pain interference [21]. Older AAs are at an increased risk of loneliness and social isolation than their White counterparts [22]. Older AAs report hopelessness, poor appetite, social isolation, difficulty concentrating, and decreased interpersonal relations as symptoms of depression [23,24], which may differ than the symptoms in Whites [25-43]. In addition, Hudson and colleagues (2018) revealed that middle-aged AAs identify many barriers to depression treatment, including cultural stigma, mistrust of health care, and being unable to afford treatment [44]. Little is known about depression treatment prevalence, help-seeking behavior, and related factors among underserved older AAs.

Critical Race Theory (CRT) is a useful framework to understand why depression is commonly left untreated in the AA community. CRT suggests that structural racism is more important than individual racism. CRT suggests that racism operates within the societal systems and institutions that are affected and influenced by an oppressive system that systematically excludes minorities. Health care system is one of the many institutions that can be affected by CRT. In the current study, we used CRT to study factors associated with the utilization of depression treatment in the AA community [45]. CRT explains how minority groups are racialized in the society. CRT expands the discourse of minority groups to highlight their lived experiences and the effects of living in a society characterized by structural racism [46]. This type of racism, defined at the macro level, sustains health inequities in many forms, including unequal resources and disproportionate access to medical treatment. Further, it has had major effects on the income, educational attainment, poverty, and health status of older AAs who are historically marginalized [47]. This theory posits that structural racism is more important than individual racism due to its operation within systems, such as health care institutions [47]. This may explain the disparity of AAs receiving less depression treatment than Whites, due to structurally unequal policies and resources, informed by institutional racism. Guided by CRT, this study seeks to understand related factors of untreated depression that are largely affected by structural racism and forms of discrimination among people who have faced racial discrimination throughout their lifetime. The need for depression treatment (both its initiation and its continuity) among older AAs depends 
in large part on having in place the right institutional policies, the absence of which may otherwise present barriers to obtaining professional treatment [48,49].

\section{Aims}

In a sample of underserved AA older adults in south Los Angeles, the current study was conducted with three aims: (1) to find explanatory factors that were associated with untreated depression (compared to individuals with no depression), (2) to explore social and health factors that were associated with treated depression (compared to individuals with no depression), and (3) to test correlates of treated depression among individuals with depression (factors that distinguish treated from untreated depression).

\section{Methods}

\subsection{Design and Setting}

This study consisted of a cross-sectional survey of low-income AA older adults in South Los Angeles (LA), performed between 2015 and 2018.

\subsection{Institutional Review Board (IRB)}

This study protocol was approved by The Institutional Review Board (IRB) of the Charles R. Drew University of Medicine and Science (CDU), Los Angeles. All participants signed a written informed consent before enrollment in this study and received a financial inventive after enrollment.

\subsection{Process and Data Collection}

Using face-to-face interviews, data was collected on age, gender, insurance type, educational attainment, financial train, living alone, chronic medical conditions (CMCs), pain intensity, depressive symptoms, and previous depression diagnosis and treatment.

\subsection{Participants}

The study recruited AA older adults using convenience sampling in economically disadvantaged areas of South Los Angeles, such as the Compton and Watts areas. Eligibility was limited to older adults who were AA, 55 years or older, could complete an interview in English, and resided in Service Planning Area (SPA) 6. Adults were excluded based on institutionalization, other clinical trial enrollment, or poor cognitive performance, which resulted in 740 AAs adults aged 55+ years.

\subsection{Measures}

The current study collected data on age, gender, educational attainment, financial strain, living alone, CMCs, pain intensity, depressive symptoms, and pervious depression diagnosis and treatment.

\subsubsection{Dependent Variable}

Untreated depression was defined as self-reported no depression treatment in the presence of a diagnosis of clinical depression or high depressive symptoms. Participants were asked whether they were diagnosed with depression. They were also asked whether they take any medication for their depression. Finally, their depressive symptoms were measured. This study used the 15-item Geriatric Depression Scale (Short Form) (GDS-SF) to evaluate depression [50,51]. Responses were on a "yes" or "no" scale. A summary score was calculated ranging between 0 and 15, with a higher score indicating more depressive symptoms. Excellent reliability and validity has been demonstrated in the GDS-SF, and the measure has been used extensively to assess depression among older adults in both clinical and community settings [50,51]. In the current study, a cut-off of 5.0 is used. This threshold is previously used to classify individuals based on depression using the GDS-SF. 


\subsubsection{Independent Variables}

Demographic Factors. Age was an interval variable while gender was treated as dichotomous ( 1 female, 0 male), and both were covariates in this study.

Socioeconomic Status (SES). Covariates also included educational attainment and financial strain. We operationalized educational attainment as an interval variable (years of schooling), and higher scores indicated higher educational attainment. We measured financial strain using three items ( $\alpha=0.923$ ) which asked how often the participant did not have enough money for necessities like food, rent/mortgage, clothes, and utility bills. Using a 5-point Likert scale (1 never to 5 always) on each item, we built a sum score of financial strain with a range between 3 and 15, where a higher score reflected more financial strain (lower SES).

Living Arrangement. Living arrangements were also operationalized as a dichotomous variable (1 living alone, 0 living with someone else).

Insurance Type and Providers. HMO membership was treated as a dichotomous variable (1 yes, 0 no). We also asked participants to report the number of health care providers they see to manage their comorbidities, and this was treated as an interval variable.

Chronic Medical Conditions (CMCs). We asked participants whether they had ever been told by a physician that they have any of the following 11 CMCs: hypertension, heart conditions, diabetes, lipid disorder/hypercholesterolemia, cancer, asthma, osteoarthritis, thyroid disorder, chronic obstructive pulmonary disease, rheumatoid arthritis, and gastrointestinal conditions. Even though research demonstrates self-reports are a valid source of CMC information, some measurement bias is also expected [52].

Pain Intensity. Using the four subscales of the McGill Pain Questionnaire-Short Form 2 (MPQ-SF-2), we measured pain intensity [53-56]. This included 22 items asking participants about their experience over the past week of different types of pain and to rate each experience on an 11-point numeric scale ( 0 none to 10 worst possible). The MPQ-SF-2 subscales include: (a) continuity, (b) intermittence, (c) neuropathic nature, and (d) affective domain. Through averaging the responses to all questions, a total pain score was calculated, where a higher score indicated more pain intensity [53-56].

\section{Statistical Note}

We used SPSS 22.0 for data analysis. For our univariate analysis, we described our variables in the total sample as well as the following three groups: no depression, depressed but not treated, and depressed and received treatment. We used Analysis of variance (ANOVA) or Chi square test for comparison of all three groups. We used polynomial logistic regression to compare the above three groups with no-depression as the reference group. We then omitted the "no depression" group and ran binary logistic regression to test predictors of treated depression. Odds ratio (OR), 95\% confidence interval (CI), and $\mathrm{p}$ values were reported.

\section{Results}

\subsection{Participants}

Table 1 (Column 1) reports the characteristics of the study sample. This study included 740 AA individuals who were between the ages of 55 and 96 years (mean, $71.8 \pm 8.3$ ). Almost $85 \%$ of the participants were 65 years of age or older and $36 \%$ of the participants were men. More than $25 \%$ of our sample reported not having a high school diploma. Three out of five participants lived alone.

Only $25 \%$ of the sample reported receiving their medical care from a Health Maintenance Organization (HMO). Almost $58 \%$ of participants had been diagnosed with at least four physical chronic conditions $(4.01 \pm 1.95)$. Of the participants, $34 \%$ reported being diagnosed with diabetes mellitus, $14 \%$ had stroke, and $29 \%$ had heart conditions. Participants reported visiting an average of $2.19(\mathrm{SD}=1.35)$ health care providers to manage their co-morbidities. 
Table 1. Descriptive statistics and bivariate correlations between depression and independent variables $(n=740)$.

\begin{tabular}{|c|c|c|c|c|c|}
\hline \multirow{2}{*}{ Independent Variables } & \multirow{2}{*}{ Total } & \multicolumn{3}{|c|}{ Depression } & \multirow{2}{*}{$p$} \\
\hline & & $\begin{array}{l}\text { No } \\
n(\%)\end{array}$ & $\begin{array}{l}\text { Untreated } \\
n(\%)\end{array}$ & $\begin{array}{c}\text { Treated } \\
n(\%)\end{array}$ & \\
\hline & $n(\%)$ & $n(\%)$ & $n(\%)$ & $n(\%)$ & \\
\hline \multicolumn{6}{|l|}{ Gender } \\
\hline Male & $266(36)$ & $190(71)$ & $46(17)$ & $30(11)$ & 0.513 \\
\hline Female & $473(64)$ & $348(74)$ & $67(14)$ & $58(12)$ & \\
\hline \multicolumn{6}{|l|}{ Age } \\
\hline 55-64 (Young-Old) & $109(15)$ & $59(54)$ & $24(22)$ & $26(24)$ & 0.000 \\
\hline 65-74 (Mid-Old) & $360(49)$ & $269(74)$ & $54(15)$ & $37(10)$ & \\
\hline$\geq 75$ (Old-Old) & $260(36)$ & $210(81)$ & $25(10)$ & $25(10)$ & \\
\hline \multicolumn{6}{|l|}{ Educational Attainment } \\
\hline No High School Diploma & $183(25)$ & $123(67)$ & $39(21)$ & $21(11)$ & 0.033 \\
\hline High School Diploma & $556(75)$ & $415(75)$ & $74(13)$ & $67(12)$ & \\
\hline \multicolumn{6}{|l|}{ Lived Alone } \\
\hline No & $294(40)$ & $231(79)$ & 35 (12) & $28(10)$ & 0.016 \\
\hline Yes & $445(60)$ & $307(69)$ & $78(13)$ & $60(13)$ & \\
\hline \multicolumn{6}{|l|}{ HMO Membership } \\
\hline No & $477(65)$ & $348(73)$ & $70(15)$ & $59(12)$ & 0.749 \\
\hline \multirow[t]{2}{*}{ Yes } & $262(35)$ & $190(72)$ & $43(16)$ & $29(11)$ & \\
\hline & Mean (SD) & Mean (SD) & Mean (SD) & Mean (SD) & \\
\hline Financial Strains (1-5) & $4.17 \pm 1.13$ & $4.36 \pm 1.01$ & $4.75 \pm 1.24$ & $3.68 \pm 1.29$ & 0.000 \\
\hline $\begin{array}{c}\text { Number of Providers } \\
(1-10)\end{array}$ & $2.19 \pm 1.35$ & $2.12 \pm 1,25$ & $2.01 \pm 1.29$ & $2.85 \pm 1.82$ & 0.000 \\
\hline $\begin{array}{l}\text { \# of Major Chronic } \\
\text { Conditions (1-11) }\end{array}$ & $4.01 \pm 1.95$ & $3.68 \pm 1.81$ & $4.75 \pm 1.96$ & $5.50 \pm 1.86$ & 0.000 \\
\hline Level of Pain & $2.03 \pm 2.25$ & $1.49 \pm 1.76$ & $3.22 \pm 2.58$ & $3.80 \pm 2.94$ & 0.000 \\
\hline
\end{tabular}

Bold numbers are statistically significant.

\subsection{Treated and Untreated Depression}

One hundred and thirty-three or $18 \%$ of participants indicated that their physician had diagnosed them with depression. However, only $66 \%$ of them admitted that they were receiving medical care for their depressive symptoms. In addition, during the data collection of this study, another 69 participants who screened positive with moderate to severe depressive symptoms (using the GDS-SF) had never been diagnosed by their providers for depression. Together, $201(27 \%)$ participants indicated that their providers diagnosed them with depression or, during collection of data, screened positive with moderate to severe depression. However, only $44 \%$ (88/201) of these individuals were receiving medical interventions for their depressive symptoms.

\subsection{Bivariate Analysis}

Table 1 (Columns 2-5) presents bivariate associations between depression and other variables. As this table shows, age, educational attainment, living arrangement, financial strain, number of providers, number of physical chronic conditions, and level of pain were all associated with having and being treated for depression. Adults 75 years of age and older were more likely to be left untreated for depressive symptoms compared to middle-aged participants. Participants with no high school diploma, those living alone, and those with a higher level of financial strain also were less likely to receive treatment for their depressive symptoms. Participants with a higher number of physical 
chronic conditions and a higher level of pain were at a higher risk of suffering from depression and had a higher chance of receiving medical intervention for depression than their counterparts with a lower level of pain and a lower number of physical chronic conditions.

\subsection{Multinomial Logistic Regression}

Table 2 shows the summary of the results of a multinomial regression model with a three-level outcome: no depression, untreated depression, and treated depression. Age, educational attainment, financial strain, number of providers, level of pain, and number of chronic conditions were associated with untreated or treated depression.

Comparing the middle-aged and the oldest (75 years and older) participants, middle-aged participants had a higher probability of belonging to the untreated group of survey respondents. The odds of untreated depression increased 2.471 times (95\% CI: 1.187-5.146) for middle aged participants (55-64), compared with participants with no depression. Similarly, respondents with no high school diploma were 0.542 times (95\% CI: 0.591-0.904) less likely to be untreated for depression, compared with participants who have a high school diploma. (Table 2)

Controlling for all other variables, a higher level of financial strain increased the odds of having depression but being untreated for it by 1.369 (1/0.731 = 1.369 95\% CI: 0.591-0.904) times, compared with those with no depression. However, financial strain was not associated with having depression and receiving medical intervention for depression, compared with those with no depression (OR: 0.898; 95\% CI: 0.693-1.164).

Table 2 shows that, controlling for all other relevant variables, the odds of receiving medical intervention for depression increases 1.247 times (95\% CI: 1.049-1.483) when the participant has more providers, compared with those with no depression. However, the number of providers was not different between those with untreated depression and those with no depression (OR: 0.881; 95\% CI: 0.721-1.076).

Participants suffering from a higher number of chronic conditions were more likely to have depression but not receive medical treatment for it (OR: 1.188; 95\% CI: 1.035-1.363), or to have depression and receive medical treatment for it (OR: 1.348; 95\% CI: 1.154-1.576), compared with those with no depression. However, the odds ratio was stronger for being under care than for not being under care for depression (OR: 1.348 vs. 1.188).

Similarly, a higher level of pain was associated with higher odds of having depression but not receiving medical treatment (OR: 1.278; 95\% CI: 1.132-1.442) or having depression and receiving medical treatment (OR: 1.219; 95\% CI: 1.089-1.363) when compared with no depression.

Table 2. Multinomial logistic regression on factors associated with treated depression and depressed but with no medical care, compared to no depression.

\begin{tabular}{ccccccc}
\hline \multirow{2}{*}{ Independent Variables } & \multicolumn{3}{c}{ Untreated Depression } & \multicolumn{3}{c}{ Treated Depression } \\
\cline { 2 - 7 } & OR & $\mathbf{9 5 \%}$ CI & $p$ & OR & $\mathbf{9 5 \%}$ CI & $p$ \\
\hline Gender & & & & & & \\
\hline Male & 0.856 & $0.521-1.407$ & 0.541 & 0.831 & $0.469-1.474$ & 0.527 \\
Female & 1.00 & & & & & \\
\hline Age & & & & & & \\
\hline $55-64$ & $\mathbf{2 . 4 7 1}$ & $\mathbf{1 . 1 8 7 - 5 . 1 4 6}$ & $\mathbf{0 . 0 1 6}$ & 2.189 & $0.975-4.915$ & 0.058 \\
$65-74$ & 1.756 & $0.988-3.092$ & 0.051 & 0.917 & $0.499-1.687$ & 0.782 \\
$\geq 75$ & $\mathbf{1 . 0 0}$ & & & & & \\
\hline
\end{tabular}


Table 2. Cont.

\begin{tabular}{ccccccc}
\hline \multirow{2}{*}{ Independent Variables } & \multicolumn{3}{c}{ Untreated Depression } & \multicolumn{3}{c}{ Treated Depression } \\
\cline { 2 - 7 } & OR & $\mathbf{9 5 \%}$ CI & $p$ & OR & $\mathbf{9 5 \% ~ C I ~}$ & $p$ \\
\hline Educational Attainment & & & & & & \\
\hline $\begin{array}{c}\text { No High School Diploma } \\
\text { High School Diploma }\end{array}$ & $\mathbf{0 . 5 4 2}$ & $\mathbf{0 . 3 2 6 - 0 . 9 0 2}$ & $\mathbf{0 . 0 1 8}$ & 1.291 & $0.678-2.456$ & 0.437 \\
\hline Live Alone & & & & & & \\
\hline No & 1.453 & $0.882-2.395$ & 0.142 & 1.129 & $0.642-1.984$ & 0.673 \\
Yes & 1.00 & & & 1.00 & & \\
\hline Financial Strain & $\mathbf{0 . 7 3 1}$ & $\mathbf{0 . 5 9 1 - 0 . 9 0 4}$ & $\mathbf{0 . 0 0 4}$ & 0.898 & $0.693-1.164$ & 0.416 \\
\hline HMO Membership & & & & & & \\
\hline No & 1.258 & $0.769-2.056$ & 0.361 & 0.934 & $0.531-1.641$ & 0.812 \\
Yes & 1.00 & & & 1.00 & & \\
\hline \# of Providers & 0.881 & $0.721-1.076$ & 0.213 & $\mathbf{1 . 2 4 7}$ & $\mathbf{1 . 0 4 9 - 1 . 4 8 3}$ & $\mathbf{0 . 0 1 2}$ \\
\# of Chronic Conditions of Pain & $\mathbf{1 . 1 8 8}$ & $\mathbf{1 . 0 3 5 - 1 . 3 6 3}$ & $\mathbf{0 . 0 1 5}$ & $\mathbf{1 . 3 4 8}$ & $\mathbf{1 . 1 5 4 - 1 . 5 7 6}$ & $\mathbf{0 . 0 0 0}$ \\
\hline
\end{tabular}

Bold numbers are statistically significant. Reference Category: No Depression; -12 Log Likelihood: 875.6; $d f: 20 ; \mathrm{p}$ $<0.001$; Nagelkerke $R$ Square: 0.271 .

\subsection{Multivariate Binary Logistic Regression}

Table 3 presents the results of a logistic regression model comparing untreated and treated depression. This model was tested using only 201 participants who were diagnosed by providers or who screened positive with the GDS-SF. Only three variables (age, educational attainment and number of providers) had association significant enough to differentiate untreated from treated depression. Participants with a high school diploma had 2.52 (95\% CI: 1.193-5.322) odds of receiving medical intervention for depression, compared with their counterparts with no high school diploma. In addition, participants aged 75 and older had 0.432 (95\% CI: 0.191-0.974) less odds of being treated for their depression, compared with participants who were 65-74 years old. Finally, participants who reported a higher number of providers had higher odds of receiving a medical intervention for their depression. For each additional provider, the odds of receiving care increased by 1.456 (95\% CI: 1.145-1.875) times. Controlling for all other relevant variables, the number of physical chronic conditions and level of pain were no longer associated with receiving medical interventions for depression.

Table 3. Logistic regression on distinction of untreated and treated depression among individuals with depression $(n=221)$.

\begin{tabular}{cccc}
\hline \multirow{2}{*}{ Independent Variables } & \multicolumn{3}{c}{ Treated Depression } \\
\cline { 2 - 4 } & OR & $\mathbf{9 5 \%}$ CI & $p$ \\
\hline Gender & & & \\
\hline Female & 0.915 & $0.453-1.847$ & 0.805 \\
Male & 1.00 & & \\
\hline Age & & & 0.786 \\
$\geq 75$ & 0.876 & $0.338-2.270$ & $\mathbf{0 . 0 4 3}$ \\
$65-74$ & $\mathbf{0 . 4 3 2}$ & $\mathbf{0 . 1 9 1 - 0 . 9 7 4}$ & \\
$55-64$ & 1.00 & & \\
\hline
\end{tabular}


Table 3. Cont.

\begin{tabular}{cccc}
\hline \multirow{2}{*}{ Independent Variables } & \multicolumn{3}{c}{ Treated Depression } \\
\cline { 2 - 4 } & OR & $\mathbf{9 5 \%}$ CI & $p$ \\
\hline Educational Attainment & & & \\
\hline High School Diploma & $\mathbf{2 . 5 2 0}$ & $\mathbf{1 . 1 9 3 - 5 . 3 2 2}$ & $\mathbf{0 . 0 1 5}$ \\
No High School Diploma & $\mathbf{1 . 0 0}$ & & \\
\hline Live Alone & & & 0.187 \\
Yes & 0.613 & $0.296-1.269$ & 0.231 \\
No & 1.00 & & \\
\hline Financial Strain & 1.206 & $0.887-1.638$ & 0.371 \\
\hline HMO Membership & & & \\
\hline Yes & 0.729 & $0.365-1.457$ & 0.002 \\
No & 1.00 & & 0.229 \\
\hline \# of Providers & $\mathbf{1 . 4 6 5}$ & $\mathbf{1 . 1 4 5 - 1 . 8 7 5}$ & \\
\# of Chronic Conditions & 1.073 & $0.886-1.298$ & \\
Level of Pain & 1.088 & $0.949-1.247$ & \\
\hline
\end{tabular}

Bold numbers are statistically significant.

\section{Discussion}

This study showed that among older AAs, an estimated 33\% are not receiving treatment for their depression. Furthermore, individuals who reported multiple chronic conditions, more health care providers, and a higher level of pain were more likely to have depression care. Untreated depression was associated with belonging to the oldest age cohort (75 years and older) and lower educational attainment (less than a high school diploma). This study is consistent with previous findings indicating that AAs experience lower rates of depression and mental health treatment, as well as decreased access to and quality of depression care [57-61].

As suggested by Critical Race Theory (CRT), this finding is linked to the systemic structural underpinning of mental health treatment barriers to depression among AA populations $[45,46]$. On an institutional level, treatment disparities for older AAs are linked to structural racism and discrimination, cultural mistrust, provider stereotypes and bias [62]. Even though older AAs who have a larger network of health care providers and more chronic conditions are more likely to receive depression treatment, the effects of racial disparities continue to persist. In 2010, Osborn and colleagues showed that older AAs with diabetes and depression had a lower rate of anti-depressant use compared to their White counterparts [13]. This disparity also exists among primary care and psychiatry health care providers who primarily serve non-White patients [14]. This racial inequity may be discouraging for older AAs who may find it difficult to obtain depression treatment from health care providers close to where they live.

Williams and colleagues found that only $45 \%$ of AAs with depression had received any form of treatment during their lifetime [63]. Assari showed that clinical depression is associated with higher levels of depressive symptoms in AAs than Whites [64]. In another study, he showed that depression is associated with more financial needs in AAs than Whites [25]. Blazer et al. also showed that depression among AAs is more severe and disabling than among Whites [62].

Thus, having access to higher number of providers is crucial for depression treatment. Similarly, certain conditions such as multiple chronic ailments and pain seem to push AA older adults toward treatment. This might be because of high levels of stigma associated with depression in the AA community $[65,66]$. We argue that pain and chronic medical conditions may be the primary reason AA older adults seek medical care, mainly in primary care settings. Some providers may then detect or evaluate symptoms of depression and provide treatment. 
Moreover, AAs who receive mental health services view their care less favorably compared to Whites [67], suggesting that they may encounter the lingering effects of structural racism within health care settings. Related sociocultural factors, such as race-based and cultural stigma, can affect perceptions of their treatment $[65,66]$. In 2012, Jimenez and colleagues revealed that older AAs had differing beliefs on the causes of mental problems compared to Whites, which can affect treatment decision making [68]. Religiosity and spirituality can influence treatment decisions as this population may rely on faith-based practices as a coping mechanism for depression. The population may participate in culturally-based coping behaviors, such as religious practices, and avoid professional treatment for depression [10]. AA's health risk behaviors may be indirect effects of structural factors, as posited by CRT. Treatment for depression provided by health care providers should involve consideration of sociocultural values and preferences, in addition to addressing the manifestations of structural racism rooted within specific health care settings $[23,46,69]$.

The results are important because if depression is present, lack of treatment has the potential to jeopardize the participant's health status. Failure to detect and treat depression is a risk factor of a wide range of health problems such as drug use, aggression, suicide, chronic disease, suicide, and mortality. In the absence of screening by health care providers, depression may be going undetected. Untreated depression results in worse health outcomes.

Additionally, we found that older AAs who were managing multiple chronic conditions and those who had more health care providers were more likely to be receiving treatment for depression. In 2014, Agyemang and colleagues found that AAs diagnosed with depression, comorbid diabetes, and hypertension were more likely to receive depression treatment as opposed to those diagnosed with depression alone [70]. Managing multiple conditions may necessitate frequent health care visits which can prove beneficial, since providers can routinely assess mental health status and provide timely treatment. Yet due to the myriad of patient, provider, and treatment factors, AAs may face competing clinical priorities of comorbid health conditions and experience a lack of comprehensive primary care services, resulting in inadequate treatment of their depression and poorer health outcomes [3,71,72]. Existing barriers, such as low access to mental health services by any individual regardless of minority group or age, are exacerbated by a lack of resources, such as unhurried patient-provider interactions [73]. It is imperative that AAs have a supportive collaboration with providers for optimal management of their health status, including depression and comorbidity management, which may explain our findings [74].

The findings of this study also revealed that older AAs with poor self-rated health have a higher likelihood of depression treatment. Previous studies also found that individuals with perceived poor health, including those reporting a cluster of depressive symptoms, are more likely to take advantage of mental health services [75,76]. African Americans experience poorer self-rated health compared to other groups, including Whites, an example of racial disparities. However, this study suggests there is a complex relationship between self-rated health and depression treatment, and thus demonstrates the significance of perceived health in understanding treatment decision making.

Adults between the ages of 50 and 64 years and ages 75 years and older were also less likely to have treated depression. One study found that referrals for depression treatment were fewer for adults 75 years and older compared to other age cohorts [77]. In 2016, Choi and colleagues found that in 62,763 ambulatory and primary care visits, treatment for depression was not provided in over $30 \%$ of visits by older depressed adults [78]. Providers are not paying adequate attention to depression in the oldest population, and so their patients may not be getting adequate treatment or may not be experiencing improvement in depressive symptoms following treatment [79]. This group is at a high risk of polypharmacy and medication interaction, which, coupled with the management of multiple chronic conditions, may lead to untreated depression $[8,80]$. However, further study is needed to understand the factors contributing to untreated depression among the younger-old cohort (ages 50-64 years). 
With respect to educational attainment, studies show that individuals with lower educational levels were more likely to have untreated depression [19]. It is recognized that higher educational attainment may be beneficial in ensuring older adults receive depression treatment and are adherent with medication [81,82]. Future studies should examine the effect of educational attainment on depression treatment (comparing AAs and Whites) to see if disparities are observed.

Financial strain was also found to be associated with untreated depression, which is not unsurprising among this population. In 2016, Grace et al. found mental health service use was lower among AAs, who reported greater stressful life events and financial strain, compared to Whites [83]. Szanton and colleagues reported that financially strained older AAs who received managed depression care experienced a decrease in depressive symptoms [84]. Another study reported that financial strain is a significant predictor of clinical depression on follow up among older adults being treated for depression [85]. Additionally, research indicates socioeconomic inequalities in the incidence of depression widen into older adulthood, suggesting that older adults with more financial strain and lower educational attainment are at increased risk of developing depressive symptoms [86]. Future work needs to focus on the underlying mechanisms that link financial strain and depression treatment outcomes.

Both pharmacological and alternative therapies should be utilized for this population, especially for individuals with comorbidities [87]. AAs who receive outpatient mental health care incur lower costs for inpatient and emergency medical care [88]. Yet AAs are more likely to be non-adherent to anti-depressant medication [89]. Harman, Edlund, and Fortney found that compared to Whites, AAs are more likely to receive psychotherapy but less likely to fill their anti-depressant medication [90]. Literature shows that older AAs have difficulty filling their medications due to low access to pharmacy services, lack of medication knowledge, and cost. AAs differ in their presentation of depression and other related mental health problems and may exhibit symptoms resembling a psychotic disorder, leading to misdiagnosis and inappropriate treatment [66]. Clinicians should exercise caution when evaluating treatment options for depression and should assist these individuals with medication supply and adherence.

There is growing evidence that a combination of anti-depressant therapy and non-pharmacological treatment may be beneficial for both the physical and mental health of older adults [20]. Fuentes and Aranda found that older AAs are more likely to benefit from collaborative and integrated care for depression treatment [69]. Another study by Arean et al., in 2005, showed that a collaborative care model in primary care significantly improves the rate of depression among older minorities, including AAs $[69,73]$. Faith-based organizations providing depression services also saw increased rates of AAs obtaining care compared to Whites and U.S.-born Hispanics [91]. The application of a collaborative care model for older minority adults may improve the quality of mental health care and access to resources in primary care, which should include both pharmacological treatment and managed counseling support $[73,92]$. Patient navigation programs that include these components may lead to greater willingness to receive treatment.

\section{Limitations}

This study had a few methodological limitations that were inherent to the study design. Being a cross-sectional study, causal inferences were not possible. There may be existing self-report bias. We did not cross-validate self-reported data with diagnoses in medical records. We did not include other related mental health problems such as anxiety or substance use in our analyses. Substance use may partially explain the differences between those who do and do not receive treatment. It is important to note that depression in this study was not diagnosed by a psychiatrist. Instead, participants were categorized as depressed if they self-reported their depression diagnosis or screened positive when they completed the GDS-SF. Finally, non-random sampling decreases the generalizability of the results. Despite these limitations, the findings further the literature on factors associated with depression treatment among older AAs in low-income urban settings. 


\section{Conclusions}

Among older AAs with depression residing in underserved areas, a higher number of chronic health conditions, health care providers, level of pain, and educational attainment may shape the chance of receiving treatment. Knowledge regarding these factors may help policy makers and clinicians to identify those at risk for untreated depression and to provide culturally sensitive care, including pharmacological aids (e.g., anti-depressant medications) and relevant patient and provider education. There is also a need to develop collaborative care programs that include patient navigation, resources, and guided support.

Author Contributions: M.B. designed the original study, secured funding, and conducted the study. S.C., S.A., J.C.S., C.W., M.C.E. and M.B. conceptualized this paper. M.B. analyzed the data. S.C. drafted the paper. All authors collaboratively helped with the revision and approved the final draft. All authors have read and agreed to the published version of the manuscript.

Funding: This study was supported by the Center for Medicare and Medicaid Services (CMS) Grant 1H0CMS331621 as well as the National Institute of Health (NIH) awards 54MD008149, R25MD007610, U54MD007598, U54TR001627, and 5S21MD000103.

Conflicts of Interest: The authors declare no conflict of interest.

\section{References}

1. Weinberger, A.H.; Gbedemah, M.; Martinez, A.M.; Nash, D.; Galea, S.; Goodwin, R.D. Trends in Depression Prevalence in The Usa from 2005 To 2015: Widening Disparities in Vulnerable Groups. Psychol. Med. 2018, 48, 1308-1315. [CrossRef] [PubMed]

2. Alegría, M.; Chatterji, P.; Wells, K.; Cao, Z.; Chen, C.-N.; Takeuchi, D.; Jackson, J.; Meng, X.-L. Disparity in Depression Treatment Among Racial and Ethnic Minority Populations in the United States. Psychiatr. Serv. 2008, 59, 1264-1272. [CrossRef] [PubMed]

3. Das, A.K.; Olfson, M.; Mccurtis, H.L.; Weissman, M.M. Depression in African Americans: Breaking Barriers to Detection and Treatment. J. Fam. Pract. 2006, 55, 30-39. [PubMed]

4. Comstock, G.W.; Helsing, K.J. Symptoms of Depression in Two Communities. Psychol. Med. 1977, 6, 551-563. [CrossRef]

5. Plant, E.A.; Sachs-Ericsson, N. Racial and Ethnic Differences in Depression: The Roles of Social Support and Meeting Basic Needs. J. Consult. Clin. Psychol. 2004, 72, 41-52. [CrossRef]

6. Roberts, R.E.; Stevenson, J.M.; Breslow, L. Symptoms of Depression Among Blacks and Whites in an Urban Community. J. Nerv. Ment. Dis. 1981, 169, 774-779. [CrossRef]

7. Agarwal, M.; Hamilton, J.B.; Moore, C.E.; Crandell, J.L. Predictors of Depression Among Older African American Cancer Patients. Cancer Nurs. 2010, 33, 156-163. [CrossRef]

8. Bazargan, M.; Smith, J.; Saqib, M.; Helmi, H.; Assari, S. Associations Between Polypharmacy, Self-Rated Health, and Depression in African American Older Adults; Mediators and Moderators. Int. J. Environ. Res. Public Health 2019, 16, 1574. [CrossRef]

9. Hooker, K.; Phibbs, S.; Irvin, V.L.; Mendez-Luck, C.A.; Doan, L.N.; Li, T.; Turner, S.; Choun, S. Depression Among Older Adults in the United States by Disaggregated Race and Ethnicity. Gerontologist 2019, 59, 886-891. [CrossRef]

10. Ward, E.C.; Mengesha, M.M.; Issa, F. Older African American Women's Lived Experiences with Depression and Coping Behaviours. J. Psychiatr. Ment. Health Nurs. 2014, 21, 46-59. [CrossRef]

11. Simpson, S.M.; Krishnan, L.L.; Kunik, M.E.; Ruiz, P. Racial Disparities in Diagnosis and Treatment of Depression: A Literature Review. Psychiatr. Q. 2007, 78, 3-14. [CrossRef] [PubMed]

12. Pickett, Y.R.; Greenberg, R.L.; Bazelais, K.N.; Bruce, M.L. Depression Treatment Disparities Among Older Minority Home Healthcare Patients. Am. J. Geriatr. Psychiatry 2014, 22, 519-522. [CrossRef] [PubMed]

13. Osborn, C.Y.; Trott, H.W.; Buchowski, M.S.; Patel, K.A.; Kirby, L.D.; Hargreaves, M.K.; Blot, W.J.; Cohen, S.S.; Schlundt, D.G. Racial Disparities in the Treatment of Depression in Low-Income Persons with Diabetes. Diabetes Care 2010, 33, 1050-1054. [CrossRef] [PubMed]

14. Lagomasino, I.T.; Stockdale, S.E.; Miranda, J. Racial-Ethnic Composition of Provider Practices and Disparities in Treatment of Depression and Anxiety, 2003-2007. Psychiatr. Serv. 2011, 62, 1019-1025. [CrossRef] [PubMed] 
15. Joo, J.H.; Morales, K.H.; De Vries, H.F.; Gallo, J.J. Disparity in Use of Psychotherapy Offered in Primary Care Between Older African-American and White Adults: Results from A Practice-Based Depression Intervention Trial. J. Am. Geriatr. Soc. 2010, 58, 154-160. [CrossRef]

16. Strothers, H.S., III; Rust, G.; Minor, P.; Fresh, E.; Druss, B.; Satcher, D. Disparities in Antidepressant Treatment in Medicaid Elderly Diagnosed with Depression. J. Am. Geriatr. Soc. 2005, 53, 456-461. [CrossRef]

17. Stockdale, S.E.; Lagomasino, I.T.; Siddique, J.; Mcguire, T.; Miranda, J. Racial and Ethnic Disparities in Detection and Treatment of Depression and Anxiety Among Psychiatric and Primary Health Care Visits, 1995-2005. Med. Care 2008, 46, 668-677. [CrossRef]

18. Unutzer, J.; Katon, W.; Callahan, C.M.; Williams, J.W., Jr.; Hunkeler, E.; Harpole, L.; Hoffing, M.; Della Penna, R.D.; Noel, P.H.; Lin, E.H.; et al. Depression Treatment in A Sample of 1801 Depressed Older Adults in Primary Care. J. Am. Geriatr. Soc. 2003, 51, 505-514. [CrossRef]

19. Simning, A.; Van Wijngaarden, E.; Fisher, S.G.; Richardson, T.M.; Conwell, Y. Mental Healthcare Need and Service Utilization in Older Adults Living in Public Housing. Am. J. Geriatr. Psychiatry 2012, 20, 441-451. [CrossRef]

20. Mitchell, P.B.; Harvey, S.B. Depression and the Older Medical Patient-When and How to Intervene. Maturitas 2014, 79, 153-159. [CrossRef]

21. Kurlowicz, L.H.; Outlaw, F.H.; Ratcliffe, S.J.; Evans, L.K. An Exploratory Study of Depression Among Older African American Users of An Academic Outpatient Rehabilitation Program. Arch. Psychiatr. Nurs. 2005, 19, 3-9. [CrossRef] [PubMed]

22. Gonyea, J.G.; Curley, A.; Melekis, K.; Levine, N.; Lee, Y. Loneliness and Depression Among Older Adults in Urban Subsidized Housing. J. Aging Health 2018, 30, 458-474. [CrossRef] [PubMed]

23. Diefenbach, G.J.; Disch, W.B.; Robison, J.T.; Baez, E.; Coman, E. Anxious Depression Among Puerto Rican and African-American Older Adults. Aging Ment. Health 2009, 13, 118-126. [CrossRef] [PubMed]

24. Blazer, D.G.; Landerman, L.R.; Hays, J.C.; Simonsick, E.M.; Saunders, W.B. Symptoms of Depression Among Community-Dwelling Elderly African-American and White Older Adults. Psychol. Med. 1998, 28, 1311-1320. [CrossRef] [PubMed]

25. Assari, S. Race, Depression, and Financial Distress in A Nationally Representative Sample of American Adults. Brain Sci. 2019, 9, 29. [CrossRef] [PubMed]

26. Evans, M.C.; Cobb, S.; Smith, J.; Bazargan, M.; Assari, S. Depressive Symptoms Among Economically Disadvantaged African American Older Adults in South Los Angeles. Brain Sci. 2019, 9, 246. [CrossRef]

27. Moazen-Zadeh, E.; Assari, S. Depressive Symptoms Predict Major Depressive Disorder After 15 Years Among Whites but Not Blacks. Front. Public Health 2016, 4, 13. [CrossRef]

28. Assari, S. Neuroticism Predicts Subsequent Risk of Major Depression for Whites but Not Blacks. Behav. Sci. 2017, 7, 64. [CrossRef]

29. Assari, S. Combined Racial and Gender Differences in the Long-Term Predictive Role of Education on Depressive Symptoms and Chronic Medical Conditions. J. Racial Ethn. Health Disparities 2017, 4, 385-396. [CrossRef]

30. Assari, S. High Income Protects Whites but Not African Americans Against Risk of Depression. Healthcare 2018, 6, 37. [CrossRef]

31. Assari, S.; Burgard, S. Black-White Differences in the Effect of Baseline Depressive Symptoms on Deaths Due to Renal Diseases: 25 Year Follow Up of A Nationally Representative Community Sample. J. Renal Inj. Prev. 2015, 4, 127-134. [CrossRef] [PubMed]

32. Assari, S.; Burgard, S.; Zivin, K. Long-Term Reciprocal Associations Between Depressive Symptoms and Number of Chronic Medical Conditions: Longitudinal Support for Black-White Health Paradox. J. Racial Ethn. Health Disparities 2015, 2, 589-597. [CrossRef] [PubMed]

33. Assari, S.; Lankarani, M.M. Chronic Medical Conditions and Negative Affect; Racial Variation in Reciprocal Associations Over Time. Front. Psychiatry 2016, 7, 140. [CrossRef] [PubMed]

34. Assari, S.; Lankarani, M.M. Stressful Life Events and Risk of Depression 25 Years Later: Race and Gender Differences. Front. Public Health 2016, 4, 49. [CrossRef]

35. Assari, S.; Moghani Lankarani, M. Secular and Religious Social Support Better Protect Blacks Than Whites Against Depressive Symptoms. Behav. Sci. 2018, 8, 46. [CrossRef] 
36. Assari, S.; Sonnega, A.; Pepin, R.; Leggett, A. Residual Effects of Restless Sleep over Depressive Symptoms on Chronic Medical Conditions: Race by Gender Differences. J. Racial Ethn. Health Disparities 2017, 4, 59-69. [CrossRef]

37. Lankarani, M.M.; Assari, S. Association Between Number of Comorbid Medical Conditions and Depression Among Individuals with Diabetes; Race and Ethnic Variations. J. Diabetes Metab. Disord. 2015, 14, 56. [CrossRef]

38. Lankarani, M.M.; Assari, S. Positive and Negative Affect More Concurrent Among Blacks Than Whites. Behav. Sci. 2017, 7, 48. [CrossRef]

39. Watkins, D.C. Depression over the Adult Life Course for African American Men: Toward A Framework for Research and Practice. Am. J. Mens Health 2012, 6, 194-210. [CrossRef]

40. Watkins, D.C.; Abelson, J.M.; Jefferson, S.O. "Their Depression is Something Different it Would Have to Be": Findings from A Qualitative Study of Black Women's Perceptions of Depression in Black Men. Am. J. Mens Health 2013, 7, 45s-57s. [CrossRef]

41. Watkins, D.C.; Assari, S.; Johnson-Lawrence, V. Race and Ethnic Group Differences in Comorbid Major Depressive Disorder, Generalized Anxiety Disorder, and Chronic Medical Conditions. J. Racial Ethn. Health Disparities 2015, 2, 385-394. [CrossRef] [PubMed]

42. Watkins, D.C.; Smith, L.C.; Kerber, K.; Kuebler, J.; Himle, J.A. Email Reminders as A Self-Management Tool in Depression: A Needs Assessment to Determine Patients' Interests and Preferences. J. Telemed. Telecare 2011, 17, 378-381. [CrossRef]

43. Wharton, T.; Watkins, D.C.; Mitchell, J.; Kales, H. Older, Church-Going African Americans' Attitudes and Expectations About Formal Depression Care. Res. Aging 2018, 40, 3-26. [CrossRef] [PubMed]

44. Hudson, D.L.; Eaton, J.; Banks, A.; Sewell, W.; Neighbors, H. “Down in The Sewers": Perceptions of Depression and Depression Care Among African American Men. Am. J. Mens Health 2018, 12, 126-137. [CrossRef] [PubMed]

45. Ford, C.L.; Airhihenbuwa, C.O. Critical Race Theory, Race Equity, And Public Health: Toward Antiracism Praxis. Am. J. Public Health 2010, 100 (Suppl. 1), S30-S35. [CrossRef]

46. Freeman, R.; Gwadz, M.V.; Silverman, E.; Kutnick, A.; Leonard, N.R.; Ritchie, A.S.; Reed, J.; Martinez, B.Y. Critical Race Theory as A Tool for Understanding Poor Engagement Along the Hiv Care Continuum Among African American/Black and Hispanic Persons Living with Hiv in the United States: A Qualitative Exploration. Int. J. Equity Health 2017, 16, 54. [CrossRef]

47. Crewe, S.E. The Task is Far from Completed: Double Jeopardy and Older African Americans. Soc. Work Public Health 2019, 34, 122-133. [CrossRef]

48. Fortin, M.; Cao, Z.; Fleury, M.-J. A Typology of Satisfaction with Mental Health Services Based on Andersen's Behavioral Model. Soc. Psychiatry Psychiatr. Epidemiol. 2018, 53, 587-595. [CrossRef]

49. Oser, C.B.; Bunting, A.M.; Pullen, E.; Stevens-Watkins, D. African American Female Offender's Use of Alternative and Traditional Health Services After Re-Entry: Examining the Behavioral Model for Vulnerable Populations. J. Health Care Poor Underserved 2016, 27, 120-148. [CrossRef]

50. Greenberg, S.A. How to Try This: The Geriatric Depression Scale: Short Form. Am. J. Nurs. 2007, 107, 60-69. [CrossRef]

51. Burke, W.J.; Roccaforte, W.H.; Wengel, S.P. The Short Form of The Geriatric Depression Scale: A Comparison with the 30-Item Form. Top. Geriatr. 1991, 4, 173-178. [CrossRef] [PubMed]

52. Gross, R.; Bentur, N.; Elhayany, A.; Sherf, M.; Epstein, L. The Validity of Self-Reports on Chronic Disease: Characteristics of Underreporters and Implications for the Planning of Services. Public Health Rev. 1996, 24, 167-182. [PubMed]

53. Kachooei, A.R.; Ebrahimzadeh, M.H.; Erfani-Sayyar, R.; Salehi, M.; Salimi, E.; Razi, S. Short Form-Mcgill Pain Questionnaire-2 (Sf-Mpq-2): A Cross-Cultural Adaptation and Validation Study of the Persian Version in Patients with Knee Osteoarthritis. Arch. Bone Jt. Surg. 2015, 3, 45-50. [PubMed]

54. Ortner, C.M.; Turk, D.C.; Theodore, B.R.; Siaulys, M.M.; Bollag, L.A.; Landau, R. The Short-Form Mcgill Pain Questionnaire-Revised to Evaluate Persistent Pain and Surgery-Related Symptoms in Healthy Women Undergoing A Planned Cesarean Delivery. Reg. Anesth. Pain Med. 2014, 39, 478-486. [CrossRef]

55. Droz, J.; Howard, F.M. Use of the Short-Form Mcgill Pain Questionnaire as A Diagnostic Tool in Women with Chronic Pelvic Pain. J. Minim. Invasive Gynecol. 2011, 18, 211-217. [CrossRef] 
56. Strand, L.I.; Ljunggren, A.E.; Bogen, B.; Ask, T.; Johnsen, T.B. The Short-Form Mcgill Pain Questionnaire as An Outcome Measure: Test-Retest Reliability and Responsiveness to Change. Eur. J. Pain 2008, 12, 917-925. [CrossRef]

57. Shao, Z.; Richie, W.D.; Bailey, R.K. Racial and Ethnic Disparity in Major Depressive Disorder. J. Racial Ethn. Health Disparities 2016, 3, 692-705. [CrossRef]

58. Lee, S.; Matejkowski, J.; Han, W. Racial-Ethnic Variation in Mental Health Service Utilization Among People with A Major Affective Disorder and A Criminal History. Community Ment. Health J. 2017, 53, 8-14. [CrossRef]

59. Jackson, J.S.; Neighbors, H.W.; Torres, M.; Martin, L.A.; Williams, D.R.; Baser, R. Use of Mental Health Services and Subjective Satisfaction with Treatment Among Black Caribbean Immigrants: Results from the National Survey of American Life. Am. J. Public Health 2007, 97, 60-67. [CrossRef]

60. Neighbors, H.W.; Woodward, A.T.; Bullard, K.M.; Ford, B.C.; Taylor, R.J.; Jackson, J.S. Mental Health Service Use Among Older African Americans: The National Survey of American Life. Am. J. Geriatr. Psychiatry 2008, 16, 948-956. [CrossRef]

61. Xiang, X.; Leggett, A.; Himle, J.A.; Kales, H.C. Major Depression and Subthreshold Depression Among Older Adults Receiving Home Care. Am. J. Geriatr. Psychiatry 2018, 26, 939-949. [CrossRef]

62. Hankerson, S.H.; Suite, D.; Bailey, R.K. Treatment Disparities Among African American Men with Depression: Implications for Clinical Practice. J. Health Care Poor Underserved 2015, 26, 21-34. [CrossRef] [PubMed]

63. Williams, D.R.; González, H.M.; Neighbors, H.; Nesse, R.; Abelson, J.M.; Sweetman, J.; Jackson, J.S. Prevalence and Distribution of Major Depressive Disorder in African Americans, Caribbean Blacks, and Non-Hispanic Whites: Results From the National Survey of American Life. Arch. Gen. Psychiatry 2007, 64, 305-315. [CrossRef] [PubMed]

64. Assari, S.; Moazen-Zadeh, E. Ethnic Variation in The Cross-Sectional Association Between Domains of Depressive Symptoms and Clinical Depression. Front. Psychiatry 2016, 7, 53. [CrossRef] [PubMed]

65. Conner, K.O.; Copeland, V.C.; Grote, N.K.; Koeske, G.; Rosen, D.; Reynolds, C.F., III; Brown, C. Mental Health Treatment Seeking Among Older Adults with Depression: The Impact of Stigma and Race. Am. J. Geriatr. Psychiatry 2010, 18, 531-543. [CrossRef] [PubMed]

66. Plowden, K.O.; Thompson Adams, L.; Wiley, D. Black and Blue: Depression and African American Men. Arch. Psychiatr. Nurs. 2016, 30, 630-635. [CrossRef]

67. Cai, A.; Robst, J. The Relationship Between Race/Ethnicity And The Perceived Experience Of Mental Health Care. Am. J. Orthopsychiatry 2016, 86, 508-518. [CrossRef]

68. Jimenez, D.E.; Bartels, S.J.; Cardenas, V.; Dhaliwal, S.S.; Alegria, M. Cultural Beliefs and Mental Health Treatment Preferences of Ethnically Diverse Older Adult Consumers in Primary Care. Am. J. Geriatr. Psychiatry 2012, 20, 533-542. [CrossRef]

69. Fuentes, D.; Aranda, M.P. Depression Interventions Among Racial and Ethnic Minority Older Adults: A Systematic Review Across 20 Years. Am. J. Geriatr. Psychiatry 2012, 20, 915-931. [CrossRef]

70. Agyemang, A.A.; Mezuk, B.; Perrin, P.; Rybarczyk, B. Quality of Depression Treatment in Black Americans with Major Depression and Comorbid Medical Illness. Gen. Hosp. Psychiatry 2014, 36, 431-436. [CrossRef]

71. Katon, W.J. Epidemiology and treatment of depression in patients with chronic medical illness. Dialog. Clin. Neuro. 2011, 13, 7.

72. Jolles, M.P.; Haynes-Maslow, L.; Roberts, M.C.; Dusetzina, S.B. Mental Health Service Use for Adult Patients with Co-Occurring Depression and Physical Chronic Health Care Needs, 2007-2010. Med. Care 2015, 53, 708-712. [CrossRef] [PubMed]

73. Arean, P.A.; Ayalon, L.; Hunkeler, E.; Lin, E.H.; Tang, L.; Harpole, L.; Hendrie, H.; Williams, J.W., Jr.; Unutzer, J.; Investigators, I. Improving Depression Care for Older, Minority Patients in Primary Care. Med. Care 2005, 43, 381-390. [CrossRef]

74. Ajuwon, A.M.; Love, R. Type 2 Diabetes and Depression in the African American Population. J. Am. Assoc. Nurse Pract. 2019, 32, 120-127. [CrossRef]

75. Jang, Y.; Yoon, H.; Chiriboga, D.A.; Molinari, V.; Powers, D.A. Bridging the Gap Between Common Mental Disorders and Service Use: The Role of Self-Rated Mental Health Among African Americans. Am. J. Geriatr. Psychiatry 2015, 23, 658-665. [CrossRef]

76. Burns, B.J.; Ryan Wagner, H.; Gaynes, B.N.; Wells, K.B.; Schulberg, H.C. General Medical and Specialty Mental Health Service Use for Major Depression. Int. J. Psychiatry Med. 2000, 30, 127-143. [CrossRef] 
77. Walters, K.; Falcaro, M.; Freemantle, N.; King, M.; Ben-Shlomo, Y. Sociodemographic Inequalities in the Management of Depression in Adults Aged 55 and Over: An Analysis of English Primary Care Data. Psychol. Med. 2018, 48, 1504-1513. [CrossRef]

78. Choi, N.G.; Dinitto, D.M.; Marti, C.N.; Kunik, M.E. When Depression is Diagnosed, Older Adults Are as Likely as Younger Adults to Be Prescribed Pharmacotherapy and Psychotherapy. Gen. Hosp. Psychiatry 2016, 43, 6-11. [CrossRef]

79. Fischer, L.R.; Wei, F.; Solberg, L.I.; Rush, W.A.; Heinrich, R.L. Treatment of Elderly and Other Adult Patients for Depression in Primary Care. J. Am. Geriatr. Soc. 2003, 51, 1554-1562. [CrossRef]

80. Bazargan, M.; Smith, J.L.; King, E.O. Potentially Inappropriate Medication Use Among Hypertensive Older African-American Adults. BMC Geriatr. 2018, 18, 238. [CrossRef]

81. Siegel, M.J.; Lucas, J.A.; Akincigil, A.; Gaboda, D.; Hoover, D.R.; Kalay, E.; Crystal, S. Race, Education, and the Treatment of Depression in Nursing Homes. J. Aging Health 2012, 24, 752-778. [CrossRef] [PubMed]

82. Rolnick, S.J.; Pawloski, P.A.; Hedblom, B.D.; Asche, S.E.; Bruzek, R.J. Patient Characteristics Associated with Medication Adherence. Clin. Med. Res. 2013, 11, 54-65. [CrossRef] [PubMed]

83. Grace, S.L.; Tan, Y.; Cribbie, R.A.; Nguyen, H.; Ritvo, P.; Irvine, J. The Mental Health Status of Ethnocultural Minorities in Ontario and Their Mental Health Care. BMC Psychiatry 2016, 16, 47. [CrossRef] [PubMed]

84. Szanton, S.L.; Thorpe, R.J., Jr.; Gitlin, L.N. Beat the Blues Decreases Depression in Financially Strained Older African-American Adults. Am. J. Geriatr. Psychiatry 2014, 22, 692-697. [CrossRef] [PubMed]

85. Cohen, C.I.; Goh, K.H.; Gustave, M. A Prospective Study of Outcome and Predictors of Subclinical and Clinical Depression in An Older Biracial Sample of Psychiatric Outpatients. J. Affect. Disord. 2010, 121, 204-211. [CrossRef] [PubMed]

86. Green, M.J.; Benzeval, M. The Development of Socioeconomic Inequalities in Anxiety and Depression Symptoms Over the Lifecourse. Soc. Psychiatry Psychiatr. Epidemiol. 2013, 48, 1951-1961. [CrossRef] [PubMed]

87. Zis, P.; Daskalaki, A.; Bountouni, I.; Sykioti, P.; Varrassi, G.; Paladini, A. Depression and Chronic Pain in the Elderly: Links and Management Challenges. Clin. Interv. Aging 2017, 12, 709-720. [CrossRef]

88. Cook, B.L.; Liu, Z.; Lessios, A.S.; Loder, S.; Mcguire, T. The Costs and Benefits of Reducing Racial-Ethnic Disparities In Mental Health Care. Psychiatr. Serv. 2015, 66, 389-396. [CrossRef]

89. Kales, H.C.; Kavanagh, J.; Chiang, C.; Kim, H.M.; Bishop, T.; Valenstein, M.; Blow, F.C. Predictors of Antidepressant Nonadherence Among Older Veterans with Depression. Psychiatr. Serv. 2016, 67, 728-734. [CrossRef]

90. Harman, J.S.; Edlund, M.J.; Fortney, J.C. Disparities in the Adequacy of Depression Treatment in the United States. Psychiatr. Serv. 2004, 55, 1379-1385. [CrossRef]

91. Dalencour, M.; Wong, E.C.; Tang, L.; Dixon, E.; Lucas-Wright, A.; Wells, K.; Miranda, J. The Role of Faith-Based Organizations in the Depression Care of African Americans and Hispanics in Los Angeles. Psychiatr. Serv. 2017, 68, 368-374. [CrossRef] [PubMed]

92. Hall, C.A.; Reynolds-Iii, C.F. Late-Life Depression in the Primary Care Setting: Challenges, Collaborative Care, and Prevention. Maturitas 2014, 79, 147-152. [CrossRef] [PubMed]

(C) 2020 by the authors. Licensee MDPI, Basel, Switzerland. This article is an open access article distributed under the terms and conditions of the Creative Commons Attribution (CC BY) license (http://creativecommons.org/licenses/by/4.0/). 